\title{
Dissonant roles: The experience of Māori in cancer care
}

\section{Abstract}

Indigenous peoples have poorer health outcomes than their non-indigenous counterparts and this applies to cancer outcomes for Māori in Aotearoa/New Zealand. Differential access to and quality of healthcare contributes to poorer survival rates for Māori. This research provides insight into some of the mechanisms that hinder and facilitate care access. Thirty four people who had undergone cancer treatment (19 Māori and 15 non-Māori) were interviewed by two Māori researchers. The analysis of the interview transcripts was informed by membership categorization analysis. This form of analysis attends to the categories that are used and the activities and characteristics associated with those categories. From this analysis it is argued that the classical patient role, or sick role, inadequately captures the kind of role that some Māori take in relation to their healthcare. Māori can also have culturally specific family (whānau) influences and a greater draw towards alternative approaches to healthcare. Dissonant roles contribute to a different experience for Māori. A better understanding of the categories and roles that are relevant to those who have cancer provides opportunities to attenuate the monocultural impacts of healthcare.

\section{Keywords}

New Zealand; indigenous health; health inequity; discrimination; categorization analysis; sick role; cultural dissonance

\section{Introduction}

Indigenous peoples throughout the world suffer from poorer health outcomes than their settler or colonizer compatriots (Kaholokula et al., 2009; Labonté, 2008). It is a common experience for indigenous peoples to receive poorer quality of healthcare than the majority group (Paul et al., 2012). In Aotearoa/New Zealand, Māori are more likely to attend health practitioners in later acute 
stages of illness (Penney et al., 2011), have delayed referrals and receive lower quality hospital care (Nikora et al., 2011). Further, although access to primary care has improved for Māori, multiple morbidities and time pressures at consultation result in missed opportunities for preventive care and earlier intervention (Cunningham et al., 2014).

Cancer is the second leading cause of death for Māori and a leading cause of health inequities between Māori and non-Māori (Blakely et al., 2011). Māori are 18\% more likely than non-Māori to be diagnosed with cancer and have a 93\% higher mortality rate (Blakely et al., 2007). Research on colon cancer has found that the most important factors associated with poorer survival in this context were patient comorbidity, access to healthcare and quality of cancer treatment (Hill et al., 2010a).

This article reports on research undertaken to better understand the impact of ethnicity on patient cancer journeys in Aotearoa/New Zealand. The journey a person with cancer must follow is complex (Cormack et al., 2005; Hill et al., 2010a). Typically, people receive care from multiple specialists in multiple settings sometimes remote from their home. Along this journey they must make many critical decisions regarding treatment options, family, finances and transport.

Walker et al. (2008) explored the experiences of Māori across the cancer journey and Māori views about how to address the concerns they raised. This research highlighted complex issues in relation to cancer inequity for Māori at a range of levels: health system, healthcare process, and patient level factors. In terms of health system factors, participants identified a number of ways to improve cancer services including co-ordinated service delivery, informing Māori of their entitlements, an increased Māori workforce, putting systems in place that provide good information (preferably faceto-face), making support and counselling available for patients and whānau (families) and more regular provision of services in rural areas. The research highlighted the importance of whānau involvement in the cancer journey, taking an holistic approach to health, and emotional and spiritual 
support from within the patient's own culture. Māori spoke of the need for a mixture of the clinical and the holistic aspects of health that takes into account wairua (spirituality), whakawhānaungatanga (relationships), and whakapapa (genealogy) (Walker et al., 2008).

The research reported in this article aims to deepen our understanding of the production of health inequities that may arise from access to healthcare through the analysis of 34 interviews with people who had undergone cancer treatment. The interpretation provided in this article was informed by membership categorization analysis (MCA). MCA was used as a way of exploring the categories respondents used or described and the rights, obligations and the shaping of the moral order for cancer patients. This analysis allowed for an interpretation of the different roles that respondents aligned with and any potential dissonances in roles relevant to particular healthcare situations. As the analysis developed the concept of the sick role and its limitations became a point of analytic focus.

MCA has been described as the analysis of 'social structure in action' (Lepper, 2000). A membership categorization device $(M C D)$ is a collection of categories with rules on how these categories are applied, for example the MCD of 'family'. Within this device there are particular categories such as mother and child, and with each of these categories certain responsibilities, obligations and so forth apply. That is, there are category bound activities. A category that is made relevant in any particular situation is tied to a characteristic or expectation of that category, called a predicate, for example a predicate of being a 'mother' is to 'care' (Stokoe, 2012). People can identify with different categories contemporaneously and what category we identify with or are identified as influences how we are expected to act and how we are perceived. Identifying with the category of Professor is quite different from identifying with the category of mother of three, even though the same person can be identified in either way (Baker, 2004). 
In the treatment of life-threatening conditions in contemporary healthcare settings people become patients and in the sociological literature the concept of sick role has been used to outline the rights and obligations of patients. For Talcott Parsons, who developed the concept, health is "the state of optimum capacity of an individual for the effective performance of the roles and tasks for which he [sic] has been socialized" (Parsons, 1958). Illness is an incapacity of an individual to effectively perform social roles. Parsons identified a number of features of the sick role. One is that recovery depends upon a therapeutic process. In this sense the patient is not responsible for recovery but the therapeutic agent is. Another feature is that illness exempts one from normal role obligations, but this must be seen as undesirable and the patient must try to get well. In trying to get well the patient is obliged to seek help from competent agencies. As a consequence health professionals have certain rights, which include the right to invade the patient's privacy and instigate treatment. The rights and obligations of patients and health professionals are not simply the product of a particular culture or of people's personalities, but are primarily the product of a social system (Gerhardt, 1987). There has been much debate about the relevance of the sick role in sociological theorising. Criticisms have included its functionalist underpinnings, which fail to emphasise dysfunction (McLennan, 2011), its conservative ideology supporting the status quo, failing to view individuals as active agents of change (Swingewood, 1984) and a failure to address factors like class, gender and ethnicity (Williams, 2005). In line with the latter critique the findings of this research suggest that the sick role inadequately captures the kind of role that some Māori take in relation to their healthcare.

\section{Methods}

This research was part of a multiple-phased research program that used qualitative methods to explore the cancer care journey of patients and how aspects of healthcare delivery may lead to inequitable outcomes for Māori. Ethics approval for this research was granted by the New Zealand 
Multi-region Ethics Committee. For the research reported here, we analysed interviews with Māori and non-Māori who were having or have completed cancer treatment.

Thirty-four respondents were recruited through community networks of local community health services, Māori Health Units in two hospitals, and doctors and nurses at four different clinics. A purposeful sample of Māori and New Zealand European (NZE) patients, and patients with and without comorbidity was sought from the lower North Island of Aotearoa/New Zealand. Following informed consent, patients were interviewed using a semi-structured format to explore in detail their cancer journey. Interviews were conducted by two Māori researchers (CD and HT). Patients were asked what prompted initial consultations within primary care, what options were discussed, the nature of interactions with formal secondary and tertiary healthcare sectors as well as with others such as whānau, friends, and colleagues, outside of health services. They were asked to discuss what enhanced their journey, what detracted from it and how their journey could have been made easier. Questions were also asked about their use of alternative therapeutic approaches, whether they were treated respectfully by staff, whether they thought they received poorer care than others and whether they experienced discrimination. Interviews were digitally recorded and transcribed and notes were taken after the interview. Alpha-numeric pseudonyms (P1 - P34) were used to protect participant confidentially. Transcripts were entered into NVivo and coded to an agreed coding frame by LS, CC, CH and KD. The use of MCA was undertaken to consider the different categories that participants used and the predicates associated with them. The analysis was undertaken by Māori and non-Māori research team members. The NVivo reports generated from the coding were used in conjunction with the MCA to identify and interpret tensions for Māori cancer patients when taking on the sick role.

\section{Findings}


The sample of 34 includes 19 participants who self-selected Māori and 15 NZE when asked about their ethnicity. There were 19 female and 15 male respondents with an average age of 61 years. Māori participants were on average five years younger (59) than non-Māori (64). The most common form of cancer reported in the sample was breast cancer $(n=10)$, followed by lymphoma $(n=5)$, and prostate cancer $(n=3)$.

An overall observation from the accounts provided is that the cancer care experience can be chaotic, not always following a linear and logical pathway. A contributing factor to this chaos is that participants can and do identify with different categories and roles in relation to their interaction with health services. Māori participants have available to them the possibility of identifying with, or being identified with, the category of Māori. This identification with 'Māori' is not available to nonMāori. On first reading this may appear tautological, that Māori identify as Māori and non-Māori do not. However, it is not the case from the data that all Māori participants identify with the category Māori in the same way. This difference reflects the view that Māori are not an homogenous group but are diverse in terms of social, political and cultural positioning (Durie, 1994). But from their accounts some clearly have a strong sense of identification with Māori, and these data allow us to explore some of the predicates and activities of this category. The following sections on the use of alternative therapies, the bearing of whānau, and discrimination, illustrate potent influences on Māori that can impact on their cancer care experience. This is followed by a section on respect, embarrassment, and care that illustrates some important issues that apply to any social group in a healthcare situation, but take particular forms for some Māori receiving cancer treatment.

\section{Use of alternative therapies}

Responses to a diagnosis of cancer can be explored by considering attitudes to alternative and traditional therapies (see Table 1). Out of the 15 non-Māori respondents who answered the question about the use of alternative therapies 14 had not used them in relation to their cancer, although of 
these, four stated that they had considered it. For non-Māori who had considered it but rejected it, their responses included P20's concern over efficacy and cost, "somebody's going to make a lot of money out of me for nothing" and for P31 and P32 a lack of perceived need. In these responses there is no sense of a strong external pressure to consider the use of alternatives. In the one case where a non-Māori respondent had used alternative therapies (P35), they were used prior to the diagnosis of cancer.

Table 1: Use of alternative therapies

\begin{tabular}{|l|l|l|l|l|}
\hline & \multicolumn{3}{|l|}{ Use of alternative therapies } & \\
\hline Ethnicity & Yes & No & No but had considered & Total \\
\hline Non-Māori & 1 & 10 & 4 & 15 \\
\hline Māori & 8 & 7 & 4 & 19 \\
\hline Total & 9 & 17 & 8 & 34 \\
\hline
\end{tabular}

Out of the 19 Māori respondents who answered the question about the use of alternative therapies eight had used them and seven had not in relation to their cancer although four of the latter stated that they had considered using some alternative approach. The level of use of alternative therapies ranged widely from trying something out to greater levels of immersion.

P1 made the strongest claims about traditional Māori medicine and was critical of western medicine as a system, although she was clear that she was not attacking people working within western medicine. She had been told that "you can cure yourself if you get cancer with rongoa Māori" (rongoa Māori refers to Māori therapeutics, which can include spiritual healing, plant-based medicines and massage). P1 noted specific treatments used for cancer and said "I started all of that rongoa straightaway". P6 also had a strong pull to avoid western medicine. He described his mother as very spiritual and used karakia (prayers), but also thought about "not taking any of the 
treatments... settling back home... And just spending it with whānau back home". P29 went to a Māori healer prior to diagnosis who told her that rongoa would help her but that her condition looked like cancer so to have that checked out by her "Pākehā (non-Māori) doctor". P29 "didn't trust the western medical system" because in her view it belittled Māori medicine and people were still dying under western medical treatment. She provides an account of being told by a hospital doctor that she needed to have the cancer cut out, and her response to this was very strong.

I said, "No, I'm not going that way. I'm going to stay with the rongoa". The Māori herbal way. Because it was a holistic approach. And it clashed straight away...I walked out of that meeting. I ran out...I basically said, "Get fucked to you," and left... Because I didn't like... the fact that he could sit there and pooh pooh...my way of wanting to get it fixed at that time. And basically telling me I'm a dead person if I go the rongoa way.

She continued saying the doctor told her that:

Māori patients who've gone that way have died, and I tried to tell him a lot of Pākehā patients that have gone that way have died too ... in fact I thought more people have died under the knife than under the holistic approach. So I just thought he had the cheek.... it has never left my memory.

Four of the Māori respondents mentioned using specific herbal remedies such as kawakawa (leaves of a small tree). P28 had used kawakawa on wounds and although she was told by a health professional to stop as it was "unhygienic", she kept using it. P5 used a plant for cleansing that was suggested by his grandson while he was having chemotherapy and said that "it was awesome".

P10 had not used alternatives but "wanted to know a bit more. I wanted to find out what other alternatives there are" because for her it would be "coming back to Māori." P21 had not used alternatives with the cancer treatment but thinks "about it now" as she had heard people talk about 
rongoa at the local marae (a place of cultural and social activities) and thought "I can try it." P12 had thought about "our Māori medicines" but decided against those approaches unless the orthodox approach did not work. P11 said he asked about alternative medicines. One relative who was in America had told him about a plant that could be used that was better than "chemo and radiation" and so P11 asked for information that could "prove that", but he got no further information. Proof was particularly important as P11 had another relation who had died from cancer many years before after rejecting radiation and using an alternative approach in Mexico, so P11 concluded that "I'm afraid I've got no trust in them."

Māori participants who did not pursue an alternative approach were more likely to provide an "account" to justify why they did not do so. That is, for some, accounts of not pursuing alternatives, particularly Māori-based alternatives, were accompanied by a justification. This was not as common for non-Māori who did not pursue an alternative approach. Five of the eleven Māori who did not use alternative medicines provided an "account" that could be seen as justifying non-use - and six provided no accounts or minimal accounts for non-use. A minimal account was usually a simple "no" to the question about the use of alternatives without any further elaboration. For non-Māori five of the 14 provided non-use accounts and eight provided no accounts for non-use (in one case, P35, the question was not directly posed). The cultural concordance of Māori patients and interviewers may have provided an external pressure to state that they had considered Māori-based alternative therapies, however it seems unlikely that this explains the differences in use of alternatives between the Māori and non-Māori patients.

Three of the Māori respondents who provided accounts for non-use stated that they would like to have used alternatives, wanted to know more about them, or only discovered the possibility of using them after the initial cancer treatment. This was not the case for any of the non-Māori participants. 
In this sample Māori respondents had a greater 'obligation' or 'desire' to use or to consider using Māori-based or other approaches, and if they did not use them to provide to the interviewers a rationale for why they did not.

\section{The bearing of whānau}

Many Māori spoke of the support they got from their whānau, sometimes in specific ways such as adult children accompanying them to appointments, visiting them and reciting karakia together. Other research supports the important role that whānau play for Māori affected by cancer. Walker and colleagues (2008) also found that whānau members played a central role in liaising with clinicians and this led to improved communication between patients and health professionals. Whānau members provide support and friendship, helping patients to understand information, assisting with practical tasks such as attending appointments, as well as facilitating interactions with health professionals (Slater et al., 2013).

But strong whānau connections could be a source of tension for some. P6, a Māori man, described decision-making about how to proceed with his illness as a "whānau thing" and states that "I've got everything that I need to help me through this journey: my family, my kids, my mokos (mokopuna or grandchildren), my Mum." But he describes the pressure on him when making decisions about treatment options. He reports that his "Mum" said to him:

"you need to come home... we're going to go the Māori way about this," you know. I said okay. "Otherwise you can stay in the Pākehā hospital and let them do their treatments on you, and let them poison you, and then let them burn you," and all this stuff, you know, which was...Okay. So chemotherapy is poisoning a human body, you know. Radiation is burning the inside of you. Okay. Alright. No, I'm not going to listen to any of yous, I'm going to listen to the specialist. 
So P6 resists his whānau and he resolves this tension by trusting the 'experts' but giving weight to whānau support, like karakia and aroha (usually translated as love), that does not interfere with western medicine.

In addition P6 refers to an incident where his sister expressed anger at him "because like she knew ... that cancer's not in our family". It is not clear from the account why this makes his sister so angry, but one can speculate that a 'genetic' or 'family' risk of cancer is not part of their family history but due to this diagnosis the family must confront the possibility of future diagnoses. For some Māori a diagnosis is not simply a label applied to the individual, but can be applied, or have a more direct impact on other whānau members. This is not simply the impact of having a loved one face a lifethreatening disease, but that the whānau itself may now confront that same disease in a new way. This point is made by P1 when discussing the way the health professionals communicated information to her:

and I said, "It's good when we can understand, because then we know what's happening with us ... we can talk to our families about it." You know, just open up to them about it. So that they understand as well. Because cancer is a daunting task for Māori whānau.

This interchange demonstrates the potential dissonance between the always-role of Māori whānau member (a cultural role) and the new role as cancer patient (the sick role).

\section{Discrimination}

In contrast to the research findings that Māori patients did not have a positive perception of health professionals (Cram et al., 2003) most respondents in this research were overwhelmingly positive in their assessments of individual health practitioners and the care they received, both Māori and nonMāori. Of the 19 Māori patients only one had strongly negative comments about the overall 
treatment. Health professionals were typically given high praise, with descriptors such as "very very caring", "awesome" and "magnificent" being common.

However, in other research, Māori report experiencing higher levels of racial discrimination than other ethnic groups in Aotearoa/New Zealand, with the exception of Asian peoples (Harris et al., 2012). In this research when participants were asked if they felt they were treated differently or discriminated against the overwhelming response was that they were not. Of note, Māori have available to them interpretations of interactions as possibly discriminatory because of their perceived ethnic identity that are not so clearly available to non-Māori. P12, a Māori respondent, provides an account of being treated poorly by front desk staff that could be because of her age or her colour - "I'm brown" (but not, for example, gender). Non-Māori in a similar situation could connect poor interactions to other categories - gender, age, social class and so on, but not to colour. The interpretation of events as ethnic discrimination is embedded within a national history of discriminatory practices (Robson, 2008). P12 calls upon everyday discrimination as illustrative:

one of his friends, he says, "Oh, you Māoris and... blah blah. Yeah no, why don't you..." I say, "Excuse me." I say, "You want us to be one people." I said, "Well, on whose terms?"

P12 notes the core of this form of discrimination where it is claimed that we should all be one people and act in agreed ways. Her question relates on whose terms or culture should people act? The assumption underlying the notion of one people is that we should act in a NZE way - a form of talk and representation that she rejects.

P28 wondered if he would have got better treatment if he was not Māori, but in response to the question on whether he experienced any discrimination he said "not blatant discrimination, I think. It's there, but um you can't really say that it's discrimination, because you know, you've got to prove it." This statement highlights the difficulty of determining if covert forms of discrimination are in operation. P29 was the only Māori respondent who expressed a strongly negative assessment of her 
care, and she stated that she was not discriminated against "as a Māori patient", but she referred to "systemic" as opposed to personal discrimination against the "holistic" perspective she had, which she described as "the Māori way". She felt that her approach was dismissed by some of the health professionals she interacted with. Here again there is conflict between the role of Māori and the role of the patient.

\section{Respect, embarrassment and care}

For all social groups issues of respect and embarrassment are important elements in the experience of healthcare. This section illustrates some ways in which these issues manifested for Māori respondents.

For some Māori respondents the category of 'patient' inadequately captured the rights and obligations they expected in relation to hospital care. P6 emphasised the issue of being treated with respect. He references himself "as a Māori man", which may suggest that status issues are important here and need to be attended to. In this instance not only does he place himself clearly in the category of Māori but also of man. He provides an account of being angry that he was told about his condition by a "junior doctor", and that he should have things explained to him and not just done. In his account of when he was told of his diagnosis he says:

the doctor that they sent in was a female doctor, and she bluntly just came out ... and said to me that, "You've got cancer." Straightaway. And I... I was blown away by it, actually. She made me quite mad. It wasn't nice to be told by a... doctor who's...in the processes of learning, that I've got cancer. I mean like because it hurt me. It did hurt me.

P6 has a strong reaction to a junior female doctor bluntly conveying the diagnosis, stating that "if you're going to tell this Māori man that I've got cancer, I would have rather you know, it come from... the main doctor". If solely the category of patient was applied by P6 this would not have been 
an issue, but relevant categories at play for him were Mãori man and junior female. This is reinforced by P6 referring to a positive experience of talking with a doctor that was like a "normal man talking to a man", consistent with his Māori cultural expectations.

P11, also a Māori male, provides an account of being treated rudely by a surgeon in Australia. He stated:

he just walked in with all his students, walked straight in my room... and then starts talking. Oh. "Who the fuck are you?" He goes, "What?" I says, "Who the fuck are you? Because you just walked in with all these people I don't even know, and you're talking about some medical shit over there mate, I'm the patient." I says, "You want to talk about me, or to me, you come and ask me questions. Don't just walk in here, start (blabbing a whole lot) to all your bloody students."

In this account P11 references himself as "the patient" but is not simply taking on the role of a passive patient in a tertiary hospital, but requires acknowledgement in relation to other relevant categories as someone who has rights. The particular rights can be viewed through the perspective of social concerns for mana, or the prestige, authority and status that is associated with, in the cases outlined here, a person.

Another concern refers to respect shown for others and their dignity, known as manaakitanga (Nikora et al., 2011). Just as categories come with particular rights, they also come with particular obligations. P12 provides an account of tidying up her bed on the day of her discharge from hospital. She refers to the response she got from the nurses:

"you're not doing that. What are you doing?" But you do. You know, we like to leave our things clean, don't we. 
The "we" in the quote may be referencing Māori, women or maybe even Māori women, as the interviewers were Māori women also. This suggests that P12 is not content to be a patient, but is helping out and respecting the work that is undertaken in this space. It is possible that we can see the category of 'guest' operating here, where one does not expect others to clean up after you but you contribute in some way to the hosts.

Some Mãori spoke of using humour to lighten the mood of those having cancer treatment. In this they acted in a therapeutic way taking on a responsibility and practice to create a more positive atmosphere. P12 talks about going to day surgery for chemotherapy:

so we're sitting there, and because... they love me going there, because I had them all laughing and because I go and I sit there, and I see some that are quite new: they're sad, you know. And I look and I think, "God, if we can make... you smile or something, that's going to help you." So... I'm in one corner with my hands in this bucket of (iced water)... and he's in the corner, with his hands in a bucket. So I looked over to (another patient), and I... "God, just like cleaning water cress, isn't it." And he'd laugh...Next thing he's doing puha, he reckons. And then the nurses come in, and we said, "Would you like a rum and Coke with ice?" And they're laughing, and everyone's started to talk.

In this extract P12 draws on food preparation activities associated with Māori, such as with water cress and puha (a vegetable native to Aotearoa/New Zealand), to create humour and a positive atmosphere. P6 talks about doing what he can to help those helping him:

I do a lot of encouraging, when it comes to um the male doc... male nurses, I should say. Female nurses seem to get it first pop. It's those male nurses that have to poke around and prod around, trying to find your vein (laughs). But I give them a lot of encouragement. 
In doing so P6 is playing an active part in the hospital environment and protecting the dignity of those caring for him.

Research has found that for Māori whakamā, or shyness and embarrassment, can be an important feature of their interaction with the health system (Kidd et al., 2013). Whakamā could be intensified by the fact that any concerns or issues would often have to be addressed to non-Māori health professionals (Kidd et al., 2013). For P10 embarrassment was due to a lack of literacy as he felt he could not articulate his views, and he also did not want too much information in the consultation. Other respondents spoke of particularly embarrassing situations. P24 provides an account of dealing with an embarrassing situation:

they took me down on the wheelchair, I'm just got a dressing gown on, and then she's standing up and taking my gown off, and there's a man in there. Yeah, because I was really annoyed with that. And she pulled my gown off, and I hadn't even got to the bed. And I says, "Excuse me,"... I says, "Put my gown back on." Because I don't know who the hell this fella was...I know they had other operations they needed to get done, but this was me, and having your gown dropped, and you only got your knickers on.

P12 refers to the embarrassment of talking about her situation in the public setting of a reception area:

it's not easy, when you're standing there explaining. And of course though you do feel whakamā, and you know, you've got to stand there and tell them in front of everybody what's wrong with you, and you know, things like that. Sorry. You know, I'm not going to do that. You know. They have rooms that you can be taken into.

Some Māori respondents had particular expectations of Māori health providers. P21 provides an account of being very annoyed that a Māori social worker came to see him but just gave him a card 
and told him to get in touch if he needed anything. He described this encounter as "short and brief" but expected much more "it upset me more because she was Māori". P11 expresses frustration at not being contacted by the runanga (an administrative group of a Māori tribe). He talks of confronting the runanga and asking

"what programme has the ... runanga got for our people who are suffering with cancer ...; I don't fucking see you pricks anywhere in meetings, or even coming out saying hey, we need to help our people that's got it." I went off my rocker.

He also noted he was not contacted by the Cancer Society, but this does not elicit such a strong negative reaction.

A noticeable difference in the talk between Māori and non-Māori was the few instances where nonMāori drew attention to the quality of the facilities in a negative way. This was not observed in the talk of the Māori participants. What this might suggest is that although non-Māori appear to accommodate well to the patient role there are expectations about attending to privacy for reasons of comfort and being more concerned about issues such as hygiene. P30, a non-Māori man in his 40s, liked it when he had a private room but it was "not nice when you're in a room with three other guys and they're all round about 80 years old". P32, a non-Māori woman "preferred a room by myself" to avoid visiting hours when people would be "coughing and the spluttering". P26, a nonMāori woman, got "a bit of a shock" when she was placed in a mixed ward and "realised there was a guy on the other side" of the curtain. She was also concerned about hygiene issues and "the smell" of the toilet. There were no accounts of Māori complaining about the quality of the facilities or accommodation in this sort of way. This may be explained by Māori having different expectations of public or communal facilities, such as those they experience at marae (Māori community centres). Further, a Māori sense of hospitality - being a guest in a hospital - might preclude criticism of the host's facilities. 


\section{Discussion}

This analysis has emphasised different categories at play between Māori and non-Māori. It should be noted that similarities could also be emphasised, and there is a great deal of commonality in the accounts provided by respondents. The rationale for emphasising difference is to identify the detail in what might be pulling or pushing Māori away from mainstream western healthcare and how mainstream healthcare might be experienced in different ways with resultant implications for health outcomes.

Health professionals may take the view that they treat all patients the same (Dew et al., 2008), but patients should be treated differently and culturally relevant categories acknowledged. Reducing people to one category, patient, in a monocultural institution like a hospital can lead to the lack of recognition of other important categories, creating role dissonance where expectations about rights, obligations and characteristics clash, including cultural role dissonance where Māori values and principles are not referenced. Monocultural hospitals and health systems do not leave room, nor allow, Māori to be Māori. This is not only an issue for Māori, but for any groups whose expectations and obligations are not congruent with biomedical monoculturality. Parsons' definition of health emphasises the capacity to perform social roles. For some Māori the social roles are not split off with sickness, and are still performed. At the risk of oversimplification, for non-Māori when the category of patient is relevant they can take on the 'sick role' in a relatively straightforward manner, particularly when they are a member of the dominant culture with which the New Zealand hospital system aligns. They can place the therapeutic process in the hands of the health professionals and their other roles in life can be less salient to the healthcare interactions.

In the data presented we have examples of passive and active responses to the therapeutic environment. Non-Māori men and women may raise issues about hygiene and mixed wards in which they are placed and in which their level of comfort is compromised. This does not challenge the sick 
role as it focuses on the environment in which care takes place as opposed to the way in which the care is conducted. It does not challenge the relationship between doctor and patient and their associated responsibilities and obligations. There are also examples of Māori women and men actively working in the hospital environment - making beds, promoting a therapeutic environment, encouraging health professionals. Important predicates associated with the category of Māori include the maintaining of mana and dignity for not only oneself, but also for one's whānau and those who are hosting you, and as such the passive patient role does not always fit with the actions required in maintaining mana and dignity.

Research has shown that people respond to health concerns by seeking advice from doctors but also from family/whānau, friends and colleagues and advice may be passed down the generations or sought via the Internet (Dew et al., 2014). The research reported here indicates the ways in which some Māori challenge expert advice drawing on their own understandings and Māori therapeutic practices. Therapeutic approaches that differ from western medicine are more prominent amongst Māori in this sample, although they were usually used in combination, but when they were not being used justifications were more likely to be provided for non-use. Traditional Māori therapy can be a factor pulling away from western medicine. Its influence must also be seen in relation to broader issues of structural discrimination where holistic views or different views are not institutionally accommodated.

Health practices generally are relational practices, not the practices of individuals in a vacuum (Hodgetts et al., 2011). To facilitate the uptake of treatment the relational aspects of health practices need to be understood. Relational practices will vary by age, gender, historical moment, geographical location and so on, but also by ethnic or cultural group and by different worldviews. It is therefore important to consider the various parts that whānau play in the cancer journey as a diagnosis of cancer may be taken as a diagnosis applied to the whole whānau. Whānau provide many different forms of support, which has been well documented (Edwards et al., 2007), but this 
support can also exert pressure on decision-making about what forms of treatment to follow. The person with the diagnosis has to negotiate that process.

An Institute of Medicine (IOM) report on unequal treatment concluded that "racial and ethnic minority patients are found to receive a lower quality and intensity of healthcare and diagnostic services across a wide range of procedures and disease areas. This finding is remarkably consistent and robust" (Smedley et al., 2003, 77). The IOM authors suggest that the use of social stereotypes provides a partial explanation for the different treatment received by ethnic minorities. Stereotyping refers to the beliefs about and attitudes towards social groups that people bring to an interaction. Clinicians categorize patients in response to having to make quick judgements in dealing with complex tasks (van Ryn \& Burke, 2000). Where role dissonance for patients occurs stereotyping around patient expectations may cause interactional problems. We argue that role dissonance is a further complication of a complex interaction, and one that more attention could be paid to. We can ask how much role dissonance impacts upon health inequities between Māori and non-Māori. Hill and colleagues argue as a result of their study of colon cancer that "there is no single point in the management process at which Māori patients suddenly experience less care; rather, the impression is one of a slight disadvantage at each step" along the complex pathways of care (Hill et al., 2010b). The focus in this article on role dissonance suggests another aspect of cancer care where Māori can be disadvantaged.

Categorization analysis promotes attention to the terms we use to classify and what associations there are with the classifications. When considering the relationship between someone who provides health services and someone who seeks help for health issues we have a number of terms used to denote this pairing - doctor (or health professional) and patient, health service provider and health consumer or client. In Parsons' conception of the sick role patients become isolated and in a sense join a separate social community. In this setting the health professionals are expected to 
exhibit universalism, meaning that people are judged "according to general criteria rather than those unique to a particular person" (Williams, 2005, 141). This conceptualization of the sick role and the doctor patient relationship captures the way in which hospital healthcare delivery operates in general. But it is one that leads to potential conflict when participants in the social system of medicine are operating with a different set of role expectations and where particularism, rather than universalism, may be required. We could consider other ways of looking at the social system of the hospital by reflecting on the roots of the term 'hospital'. Hospitals, as established in early medieval Europe, were places where "strangers, pilgrims, sick and poor people could be received and cared for" (Riva \& Cesana, 2013, 2). The Latin word 'hospes' is translated as 'guest', suggesting a lodge for strangers (Riva \& Cesana, 2013). To use the language of categorization analysis, the standardised relational pairing of hosts and guests has quite different obligations and expectations to the pairing of doctors and patients. For some Māori patients the role they take on during cancer treatment may be closer to guest, and that the kind of respect guests should be shown can be at odds with the 'efficient' use of resources in hospitals.

An attempt over many years to respond to some of the concerns raised in relation to indigenous peoples' access and use of healthcare services is to promote cultural competence programmes in the education of health professionals. The goal of these programmes is to acknowledge the cultural and social influences on the consultation between the health professional and the patient and to consider or devise ways that takes these influences into account so as to facilitate better patient outcomes (Paul et al., 2012). Whether increasing practitioner knowledge translates into better health outcomes is debatable (Renzaho et al., 2013). Paul and colleagues argue that to perceive oneself as culturally competent is in fact an indication of cultural incompetence. They argue this on the basis that such a view assumes that complex historical and social processes that are constituted under the term culture cannot be reduced to a specific learnt technical skill (Paul et al., 2012). Having 'competence' suggests an achieved endpoint, as opposed to an ongoing process of learning 
and reflection. Being culturally competent requires attention to cultural processes, not just ascertaining values and beliefs (Goodkind et al., 2015). Our research suggests that if cultural competence training is extended to understanding the different roles available beyond the sick role for those who are seeking clinical care, opportunities may arise for a more equitable and less monocultural form of healthcare delivery where cultural dissonance is recognised and addressed.

\section{References}

Baker, C. (2004). Membership categorization and interview accounts. In D. Silverman (Ed.), Qualitative research: Theory, method and practice pp. 162-176). London: Thousand Oaks.

Blakely, T., Shaw, C., Atkinson, J., Cunningham, R., \& Sarfati, D. (2011). Social inequalities or inequities in cancer incidence? Repeated census-cancer cohort studies, New Zealand 19811986 to 2001-2004. Cancer Causes Control, 22, 1307-1318.

Blakely, T., Tobias, M., Atkinson, J., Yeh, L.C., \& Huang, K. (2007). Tracking Disparity: Trends in ethnic and socioeconomic inequalities in mortality, 1981-2004. Wellington: Ministry of Health.

Cormack, D., Ratima, M., Robson, B., Brown, R., \& Purdie, G. (2005). Access to Cancer Services for Māori. Wellington.

Cram, F., Smith, L., \& Johnstone, W. (2003). Mapping the themes of Māori talk about health. New Zealand Medical Journal, 116, 7.

Cunningham, C.W., Triggs, S., \& Te Hoe Nuku Roa Research Team (2014). Health of Māori in NelsonMarlborough compared to other regions. A report for the Nelson-Marlborough District Health Board based on two waves of data collected from the longitudinal study of Māori households. Wellington: Research Centre for Māori Health and Development.

Dew, K., Chamberlain, K., Hodgetts, D., Norris, P., Radley, A., \& Gabe, J. (2014). Home as a hybrid centre of medication practice. Sociology of Health \& IIIness, 36, 28-43.

Dew, K., Dowell, A., Stubbe, M., Plumridge, E., \& Macdonald, L. (2008). Treating patients differently: A qualitative study of how clinical and social factors shape interactions between doctors and patients. New Zealand Family Practice, 35, 382-386.

Durie, M. (1994). Whaiora: Māori health development. Auckland: Oxford University Press.

Edwards, S., McCreanor, T., \& Moewaka-Barnes, H. (2007). Maori family culture: A context of youth development in Counties/Manukau. Kotuitui: New Zealand Journal of Social Sciences Online, 2, 1-15.

Gerhardt, U. (1987). Parsons, role theory, and health interaction. In G. Scambler (Ed.), Sociological theory and medical sociology pp. 110-133). London and New York: Tavistock.

Goodkind, J.R., Gorman, B., Hess, J.M., Parker, D.P., \& Hough, R.L. (2015). Reconsidering culturally competent approaches to american Indian healing and well-being. Qualitative Health Research, 25, 486-499.

Harris, R., Cormack, D., Tobias, M., Yeh, L.-C., Talamaivao, N., Minster, J., et al. (2012). The pervasive effects of racism: Experiences of racial discrimination in New Zealand over time and associations with multiple health domains. Social Science \& Medicine, 74, 408-415.

Hill, S., Sarfati, D., Blakely, T., Robson, B., Purdie, G., Chen, J., et al. (2010a). Survival disparities in Indigenous and non-Indigenous New Zealanders with colon cancer: the role of patient comorbidity, treatment and health service factors. Journal of Epidemiology and Community Health, 64, 117-123. 
Hill, S., Sarfati, D., Blakely, T., Robson, B., Purdie, G., Dennett, E., et al. (2010b). Ethnicity and Management of Colon Cancer in New Zealand. Do Indigenous Patients Get a Worse Deal? Cancer, 116, 3205-3214.

Hodgetts, D., Chamberlain, K., Gabe, J., Dew, K., Radley, A., Madden, H., et al. (2011). Emplacement and everyday use of medications in domestic dwellings. Health \& Place, 17, 353-360.

Kaholokula, J., Nacapoy A., \& Dang, K. (2009). Social justice as a public health imperative for Kānaka Maoli. AlterNative: An International Journal of Indigenous Peoples, 5, 116-137.

Kidd, J., Gibbons, V., Kara, E., Blundell, R., \& Berryman, K. (2013). Oranga tāne Māori: A whānau ora journey of māori men with chronic illness. AlterNative: An International Journal of Indigenous Peoples, 9, 125-141.

Labonté, R. (2008). Introduction to Part III. In J. Green, \& R. Labonté (Eds.), Critical Perspectives in Public Health pp. 136-149). Abingdon and New York: Routledge.

Lepper, G. (2000). Categories in text and talk: A practical introduction to categorization analysis. London: Sage.

McLennan, G. (2011). Story of sociology: a first companion to social theory. London: Bloomsbury Academic.

Nikora, L.W., Hodgetts, D., Carlson, T., \& Rua, M. (2011). Māori and medications: What happens when the pills go home? AlterNative: An International Journal of Indigenous Peoples, 7, 8899.

Parsons, T. (1958). Definitions of health and illness in the light of American values. In E.G. Jaco (Ed.), Patients, physicians and illness: Sourcebook in behavioral science and medicine pp. 165-187). Glencoe: The Free Press.

Paul, D., Hill, S., \& Ewe, S. (2012). Revealing the (in)competency of "cultural competency" in medical education. AlterNative: An International Journal of Indigenous Peoples, 8, 318-328.

Penney, L., Barnes, H.M., \& McCreanor, T. (2011). The blame game. AlterNative: An International Journal of Indigenous Peoples, 7, 73-86.

Renzaho, A.M.N., Romios, P., Crock, C., \& Sonderlund, A.L. (2013). The effectiveness of cultural competence programs in ethnic minority patient-centered health careua systematic review of the literature. International Journal for Quality in Health Care, 25, 261-269.

Riva, M.A., \& Cesana, G. (2013). The charity and the care: the origin and the evolution of hospitals. European Journal of Internal Medicine, 24, 1-4.

Robson, B. (2008). What is Driving the Disparities? In Dew. Kevin, \& A. Matheson (Eds.), Understanding Health Inequalities in Aotearoa New Zealand pp. 19-31). Dunedin: Otago University Press.

Slater, T., Matheson, A., Davies, C., Tavite, H., Ruhe, T., Holdaway, M., et al. (2013). 'It's whanaungatanga and all that kind of stuff': Māori cancer patients experiences of health services. Journal of Primary Health Care, 5, 308-314.

Smedley, B., Stith, A., Nelson, A., \& Committee on understanding and elimination racial and ethnic disparities in health care (2003). Unequal treatment: confronting racial and ethnic disparities in health care. Washington D.C.: The National Academies Press.

Stokoe, E. (2012). Moving forward with membership categorization analysis: Methods for systematic analysis. Discourse Studies, 14, 277-303.

Swingewood, A. (1984). A short history of sociological thought. Houndmills: MacMillan.

van Ryn, M., \& Burke, J. (2000). The effect of patient race and socio-economic status on physician's perceptions of patients. Social Science \& Medicine, 50, 813-828.

Walker, T., Signal, L., Russell, M., Smiler, K., \& Tuhiwai-Ruru, R. (2008). The road we travel: Māori experience of cancer. New Zealand Medical Journal, 121, 3193.

Williams, S.J. (2005). Parsons revisited: from the sick role to...? Health: An Interdisciplinary Journal for the Study of Health, Illness and Medicine, 9, 123-144. 